Conferences

Конференции

Conference report

\title{
Phenomenon of Language: The Paradigms of Functional Semantics and Linguosemiotics (V Novikov Readings. Moscow, Russia, 18-19 April 2019)
}

\author{
Elena Krasina, Marina Novikova \\ RUDN University \\ 6, Miklukho-Maklaya St., Moscow, 117198, Russia
}

\section{For Citation:}

Krasina, Elena and Novikova, Marina (2019). Phenomenon of Language: paradigms of functional semantics and linguosemiotics (V Novikov Readings. Moscow, Russia, 18 -19 April 2019). Russian Journal of Linguistics. Russian Journal of Linguistics, 23 (3), 856-864. doi: 10.22363/23129182-2019-23-3-856-864.

\section{Феномен языка в парадигмах функциональной семантики и лингвосемиотики (V Новиковские чтения. Москва, 18-19 апреля 2019 г.)}

\author{
Российский университет дружбы народов \\ ул. Миклухо-Маклая, д. 6, Москва, 117198, Россия
}

Для цитирования:

Красина Е.А., Новикова М.Л. Феномен языка в парадигмах функциональной семантики и лингвосемиотики (V Новиковские чтения. Москва, 18-19 апреля 2019 г.) // Russian Journal of Linguistics. 2019. T. 23. No 3. C. 856-864. doi: 10.22363/2312-9182-2019-23-3-856-864.

Синтезирующий подход к языку позволяет утверждать, что язык предстает в единстве двух систем: и как системно-структурно образование (Н.Д. Арутюнова, 2013; В.А. Звегинцев, 2007; В.А. Карпов, 2003; И.Г. Милославский, 2013, 2019; B.M. Солнцев, 1979; É. Benveniste, 1971; Ch. Bally, 1944; G. Cuillaume, 1973; R. Jakobson, 1980), т.е. система единиц и категорий, и как семиотическая символическая система (А.Е. Бочкарев, 2014; Л.Г. Зубкова, 2010; А.Б. Соломончик, 2010; Ю.С. Степанов, 1985, 2014; L. Hjelmslev, 1953, 1961; J.M. Lotman, 1990, 2005; 


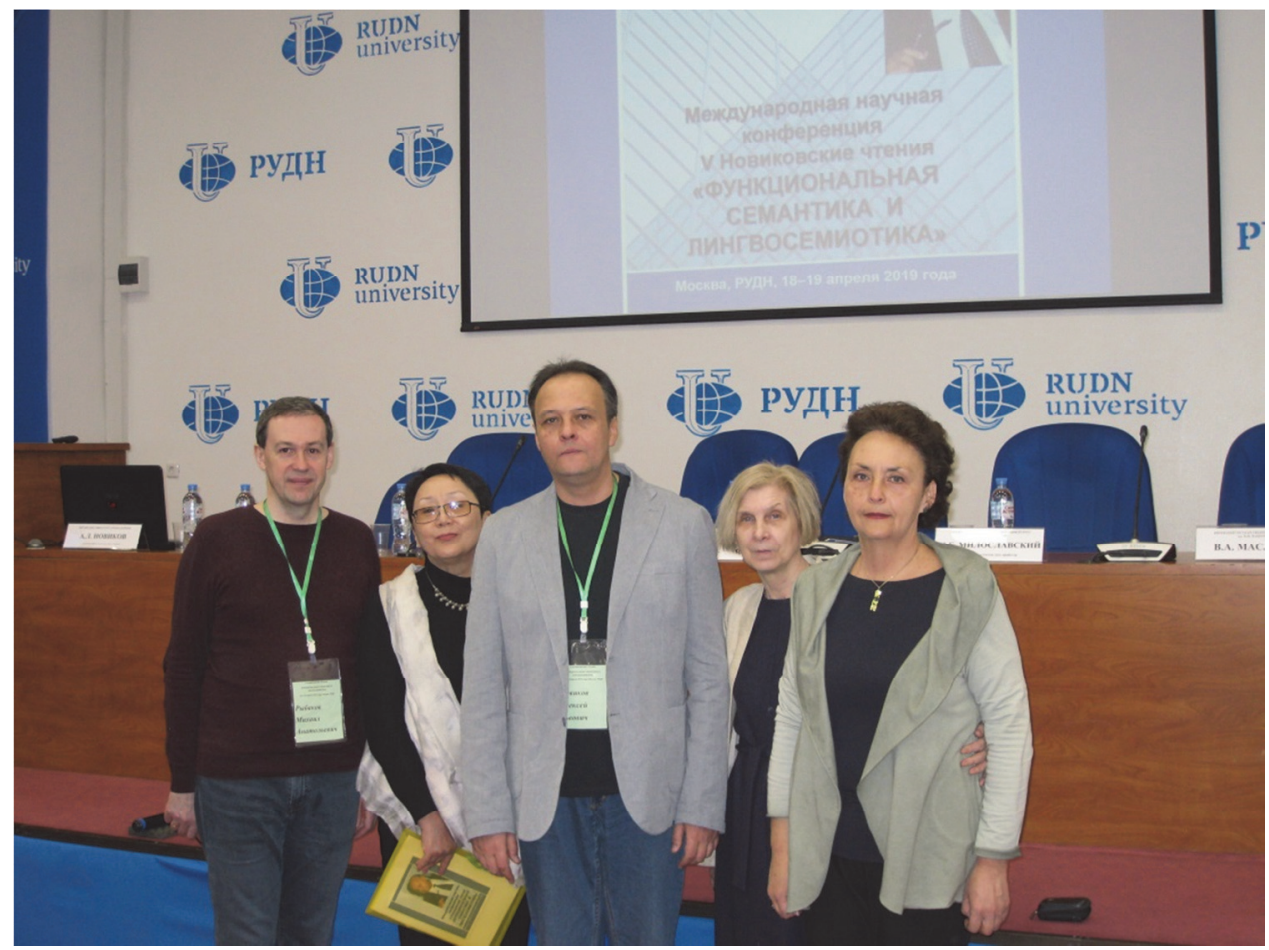

Участники конференции V Новиковские чтения

C.S. Pierce, 1994; F. de Saussure, 1977; U. Eco, 1989). Обе системы взаимодействуют между собой, наиболее тесно - в области семантики, сфере смыслов, значений и означиваний, поскольку языковое содержание демонстрирует двойственную природу - одновременно семиотическую и семантическую.

Истоки функциональной семантики описаны в лингвистических теориях $\mathrm{XX}$ века, среди которых одной из ведущих стала теория Л.А. Новикова (Новиков, 1982, 2001; Функциональная семантика, 2011). Личность Льва Алексеевича Новикова, ученого и учителя, его теоретическое наследие по праву принадлежит сегодняшнему дню и служит примером неустанных исследовательских поисков, о чем свидетельствуют регулярно проводимые в РУДН Новиковские чтения, ставшие научным форумом, привлекающим авторитетных ученых и молодых исследователей из России и из-за рубежа.

Взаимодействие семантики и семиотики, развитие функциональной семантики и лингвосемиотики охватывает широкий круг проблем гуманитарного знания - от философии до филологии. Актуальность и активность развития такого трансцедентального подхода подтверждается многообразными и многочисленными теоретическими и прикладными разработками в различных сферах человеческой деятельности, в сфере общественной коммуникации.

Функциональная семантика прорастает из семиотики, становится ее неотьемлемой частью, а семиотика позволяет выйти за пределы собственно идеальных систем языка и философии, установить связь с материальными предметами и системами. В семиозисе язык предстает как искусство, как творческий процесс, как инструмент связи с другими семиотическими системами, например, изобра- 
зительными - с декоративным искусством, орнаменталистикой, фотографией, кинематографией. Эти идеи ярко обозначились в докладе проф. В.А. Масловой (Витебск, ВГПУ им. П. Машерова) (Маслова, 2016, 2019), подчеркнувшей важность для семантики глубинной интерпретации наблюдаемых фактов от слова до текста, особенно текста художественного (Новиков, 2007), что характеризует семантическую концепцию Л.А. Новикова как полидисциплинарную и интегративную. Для постижения языка, человека и его языкового сознания, языка в человеке, культуре и обществе необходима и важна «глубинная интерпретация наблюдаемых в опыте фактов языка» (Новиков 1982:4). При этом наиболее эффективный путь к глубинному знанию - особое внимание к семантическим процессам. Ярким примером становится поэзия, поскольку она оперирует символами, имеющими диффузную имплицитную семантику. Очевидно, заключает В.А. Маслова, что Л.А. Новиков опередил время, поставив ряд вопросов, ставших актуальными только в XXI веке.

И.Г. Милославский, профессор МГУ им. М.В. Ломоносова, обратился к прикладным аспектам функциональной семантики, созвучным теоретическим постулатам Л.А. Новикова. Он сформулировал ряд задач обучения русскому языку, которые, по Л.В. Щербе, принадлежат к «активной грамматике», и главная среди них - обращение к языковому знанию и сознанию обучающихся, опора не на модели, их воспроизведение и запоминание, а на креативный подход, на коммуникативно-семантические стратегии, на глубинную интерпретацию языковых смыслов и значений (Милославский, 2013).

Совместный доклад проф. Т.Г. Хухуни и А.А. Осиповой (МГОУ, Московская область) анализирует проявления модернизации в переводе канонических текстов Священного Писания на рубеже XX-XXI веков (Хухуни, 2015). Путь от диахронического к синхроническому варианту текста всегда сложен, и переводческие стратегии вновь и вновь обращаются к семантике и прагматике, пытаясь уравновесить тексты оригинала и перевода, зачастую исходя из конфликтогенной оппозиции «архаизация vs. модернизация» в целях достижения адекватности и исключения искажения переводного текста.

Профессор М.Л. Новикова (РУДН, Москва), развивает идеи Л.А. Новикова в области лингвистического анализа художественного текста и рассматривает семантические преобразования и дискурсивную аномальность текстов с точки зрения художественных кодов, смысловой и эмоциональной многослойности поэтического слова. Лингвистическая поэтика понимает язык как искусство, как проекцию эстетического начала и объективацию эстетической функции, но при этом регулярно возникает противоречие между нормой и не-нормой, аномалией, обусловленной различными способами и средствами вербализации художественного познания и моделирования действительности. Смысловая плотность художественного текста, семантическая осложненность - его важнейшее свойство, яркое проявление эстетической функции. Словесный образ, сложные образные структуры управляются глубинными ассоциативными связями, которые обнаруживаются на различных уровнях динамической структуры художественного текста. Семантическая плотность художественного текста мотивирована концептуально и одновременно обусловлена смысловой множественностью и неоднозначностью. 
Обращаясь к поэтическому тексту, ученик и последователь Л.А. Новикова, профессор Г.В. Векшин (Московский политехнический университет, Высшая школа печати и медиаиндустрии, Москва) раскрывал и обосновывал принцип звукового равновесия в стихе, согласно которому ключевые элементы текста не должны оставаться без звукового отклика (Векшин, 2006). Программа автоматического анализа текста «Фонотекст», разработанная на основе силлабоцентрической версии звуковой организации стиха, верифицирует этот принцип и подтверждает плодотворность его действия.

Область функциональной семантики охватывает не только лексическую, но и грамматическую систему языка, используя инструменты языковой метафоры и метонимии. Об этом рассуждает М.А. Рыбаков (РУДН, Москва), рассматривая падежные значения в русском языке. В функциональной семантике полисемия и метонимия - это семантическое отношение в языке и одновременно удобный способ хранения информации, средство языковой экономии, когда один знак способен означивать ряд предметов, свойств, явлений. Применительно к системе падежных значений метонимия позволяет представить семантические смыслы и отношения как неслучайный, мотивированный переход от одних значений к другим в направлении от более конкретных к более абстрактным значениям.

Применяя металингвистический подход к анализу лексической семантики терминов, К. Беднарова-Гибова (Университет г. Прешов, Словакия) опирается на базовый принцип Ф. Шариффана (Sharifian, 2015), устанавливающий связь употребления терминов с культурной концептуализацией. Семантика термина это обязательная компонента лексической семантики в металингвистическом аспекте, тем более при обсуждении вопроса о синонимии в терминологии. Термины принадлежат языку для специальных целей и, по М. Кабре, они явные и полнозначные знаки специального языкового дискурса, конвенциональные символы понятий в отдельной области знаний (Cabré, 1999: 80-81). Поскольку синонимия опирается на сходство и/или тождество денотативных смыслов, ее присутствие в метаязыке представляется нерелевантным, но сама возможность синонимии терминов создает ситуацию «синонимических ловушек». Проиллюстрировав эти положения языковыми примерами, К. Беднарова-Гибова заключает: при языковых контактах, например, в процессе перевода, необходимо учитывать допустимую смысловую вариативность терминов и влияние культурного наследия. Таким образом, принципы функциональной семантики активно реализуются и в метаязыковом пространстве.

Лингвосемиотика представлена в многообразии тем и проблем. Так, Т.В. Маркелова (АНО ВО Институт современного искусства, Москва) обращается к анализу семантической, синтаксической и прагматической природы оценочного знакапрагмемы и сопоставляет три типа оценочных знаков - функции, коннотации, прагмемы; при этом ведущая роль в их системе отводится прагмеме: «Прагматический аспект значения слова, выделенный и теоретически обоснованный Л.А. Новиковым, позволяет дифференцировать в оценочной лексике три группы знаков - знаки-прагмемы Жизнь неприглядна; знаки-коннотации Жизнь сказочна и знаки-функции Жизнь прекрасна, которые различаются спецификой реализации прагматической функции, непосредственно связанной с их семантикой» (Марке- 
лова 2013: 49; 55). В этой триаде знаки-прагмемы реализуют одновременно и денотативное, и прагматическое значение, а в целом три типа прагматических знаков различаются по степени зависимости от контекста, шире - от репрезентации оценочного фрагмента языковой картины мира. Уникальность знака-прагмемы заключается в том, что он представляет собой своеобразное сжатое оценочное суждение, объединяя в себе основание оценки, оценочные субъект и предикат. В итоге Т.В. Маркелова формулирует следующее определение прагмемы: это динамично развивающееся лексическое средство выражения оценки, знаковая природа которого основана на прагматике, диктующей семантику связи денотативного и оценочного значений; синтактике, эксплицирующей парадигму оченочных суждений; а также «двойственной» прагматике аксиологической природы знака-прагмемы.

В докладе О.И. Максименко и П.Н. Хроменкова (МГОУ, Московская область) объектом становятся полисемиотические элементы государственных гербов, в первую очередь, цвет, геометрические формы (полоски, клетки и т.п.), иконические и символические изображения. При вербальной интерпретации этих семиотических компонентов государственной символики фактически описывается некий программный генезис политической сущности отдельного государства в диалоге с другими государствами, и в результате формируется поликодовый текст, комбинирующий невербальные и вербальные элементы программного характера. Полисемиотичность исследуемого объекта определяется в соотношении с поликодовостью передачи информации и мультимодальностью коммуникации.

Поликодовый гетерогенный текст представлен в выступлении Ю.А. Евграфовой (МГОУ, Московская область) на примере кинотекста художественного фильма «Фауст» (реж. А. Сокуров, 2011 г.). Статика и динамика фильма, его эпизодов и кадров задают статику и динамику денотативных и коннотативных смысловых соотношений. Коннотативный план, представленный культурно, социально и т.п. маркированными ассоциациями, надстраивается над планом денотативным, в котором преобладают иконические знаки, например, компоненты объектов пространства, места действия - горы, море, город и др. При этих условиях выявление коннотативных смыслов во многом зависит от средств, которые в лингвистике принято обозначать термином «троп». Троп экранного текста становится связующим звеном между денотацией и коннотацией, придавая динамику кинотексту в целом. Денотат-иконический знак в кадре фильма выполняет роль означающего двустороннего знака, а символический ассоциативный знак коннотации занимает место означаемого, а оба компонента знака объединяет семиотический механизм знака-символа. Иными словами, код задаёт означающие денотации, трансформируя предметы экранного пространства в знаки, вызывая в зрителе определенные эмоции, что, в свою очередь, является означаемым для коннотации, а способы конструирования денотации являются ее означающими. Таким образом, в гетерогенном экранном тексте при моделировании реальности конструируется смежность между отдельными денотатами, как правило, знаками-иконами или индексами, моделируется позитивная симулякративность, когда у зрителя - потребителя кинотекста возникает ощущение «реальности» происходящего на экране, а троп становится «скорописью» гетерогенного экранного текста, в основе которого лежит операция смещения или сгущения значения. 
В докладе Т.В. Поплавской (МГЛУ, Минск, Беларусь) обсуждаются проблемы нейминга семиотического пространства города, анализируются микротекстыназвания объектов городской среды, например, тексты-вывески кафе, магазинов, мастерских, кинотеатров и т.д. В целях успешной коммуникации для привлечения потребителя такие названия используют принцип языковой игры и карнавализации, по М.М. Бахтину, сравните, однотипные номинации «бар Пятницая» и «ресторан Friday» (по-английски); актуализируется национально специфический культурный компонент, например, American BBQ (Американское барбекю); BeerFest (немецкий пивной праздник); итальянская кондитерская Dolce Vita (букв. 'сладкая жизнь') и др. Эволюция смыслов происходит за счет семантического и графического обыгрывания прецедентных имен, ср.: «кафе модных напитков» Tea Funny ('чай' + 'забавно', 'смешно') призвано ассоциироваться то ли со всемирно известной ювелирной маркой Tiffany, то ли с романом Трумэна Капоте «Завтрак у Тиффани» или с его экранизацией с участием Одри Хэпберн; аналогично «рестобар ШексПИР». Распространены и номинации «несочетающихся смыслов», создающие игровой эффект: Танщующий лобстер, Зеленая собака, Винное собрание, Винная библиотека, Салон еды, Кондитерская мастерская, Flower Bar ('цветочный бар'). Все эти и многие другие примеры демонстрируют проявление в названиях и в городской семиотике в целом взаимодействие трех семиотических отношений - семантики, синтактики и прагматики, которые сопровождаются принципами поиска креативных смыслов и языковой игры.

Эстетическая функция рекламы активно обсуждается лингвистами, художниками и широкой общественностью, поскольку роль рекламы в современной коммуникации велика и неоднозначна. В исследовании проф. И.В. Бугаевой (Российский государственный аграрный университет - МСХА имени К.А. Тимирязев, Москва) материалом послужила российская реклама с религиозным компонентом, что важно для России - многоконфессионального государства. Вербальными компонентами служит религиозная лексика, характеризующая, например, продукты питания: святой, постный, освященный и под. для православных; халяль для мусульман; кошерный для иудеев. Изображения религиозных символов наряду с использованием особых шрифтов и графической техники оформляют невербальный компонент манипулятивного воздействия рекламы. Наконец, особую роль играет цветовое оформление рекламы: священный зелёный - это цвет ислама. Невербальные компоненты рекламы выполняют смыслопорождающую функцию, а их взаимодействие с вербальными компонентами позволяет реализовать в поликодовом тексте рекламы эстетическую функцию.

Как показали доклады участников конференции, функциональная семантика и семиотика закладывают базу методологии анализа познавательной деятельности, становится основой для создания новых исследовательских парадигм.

(C) Е.А. Красина, М.Л. Новикова, 2019 (c) creative

https://creativecommons.org/licenses/by/4.0/ 


\section{СПИСОК ЛИТЕРАТУРЫ / REFERENCES}

Арутюнова Н.Д. Предложение и его смысл: Логико-семантические проблемы. М.: Книжный дом «ЛИБРОКОМ», 2013. [Arutunova, N.D. (2013). Predlozheniye i jego smysl: Logikosemanticheskiye problemy. Moscow: Knizhyj dom «LIBROKOM». (In Russ.)]

Бочкарев А.Е. Семантика. Основной лексикон. Нижний Новгород: ДЕКОМ, 2014. [Bochkarev, A.E. (2014). Semantika. Osnovnoj leksikon. Nizhnij Novgorod: DEKOM. (In Russ.)]

Векшин Г.В. Очерк фоностилистики текста: Звуковой повтор в перспективе смыслообразования. М.: МГУП, 2006. [Vekshin, G.V. (2006). Ocherk fonostilistili teksta. Zvukovoj povtor v perspective smysloobrazovaniya. Moscow: MGUP. (In Russ.)]

Звегинцев В.А. Теоретическая и прикладная лингвистика: учебное пособие. Изд. 2-е. М.: Издательство ЛКИ, 2007. [Zvegintsev, V.A. (2007). Teoreticheskaya i prikladnaya lingvistika: uchebnoye posobiye. Izd. 2-e. Moscow: Izdatel'stvo LKI. (In Russ.)]

Зубкова Л.Г. Принцип знака в системе языка. М.: Языки славянской культуры, 2010. [Zubkova, L.G. (2010). Printsip znaka v sisteme jazyka. Moscow: Jazyki slavyanskoj kultury. (In Russ.)]

Карпов В.А. Язык как система. Изд. 2-е, испр. М.: Едиториал, УРСС, 2003. [Karpov, V.А. (2003). Jazyk kak sistema. Izd. 2-e, ispr. Moscow: Editorial, URSS. (In Russ.)]

Маркелова Т. В. Прагматика и семантика средств выражения оценки в русском языке. М.: МГУП им. Ивана Федорова, 2013.[Markelova, T.V.(2013). Pragmatika i semantika sredsv vyrazheniya otsenki v russkom jazyke. Moscow: MGUP im. Ivana Fyodorova. (In Russ.)]

Маслова В.А. Поэтический текст. Новые подходы и решения. М.: Флинта: Наука, 2016. [Maslova, V.A. (2016). Poeticheskiy tekst. Novyie podhodyi i resheniya. Moscow: Flinta: Nauka. (In Russ.)]

Маслова В.А. Концептуальные основы современной лингвистики. М.: Флинта: Наука, 2019. [Maslova, V.A. (2019). Kontseptualnyie osnovyi sovremennoy lingvistiki. Moscow: Flinta: Nauka. (In Russ.)]

Милославский И.Г. Говорим правильно по смыслу или по форме? М.: ACT, 2013. [Miloslavskiy, I.G. (2013). Govorim pravilno po smyislu ili po forme? Moscow: AST. (In Russ.)]

Милославский И.Г. Современный русский язык. Культура речи и грамматика. М.: Юрайт, 2019. [Miloslavskiy, I.G. (2019). Sovremennyiy russkiy yazyik. Kultura rechi i grammatika. Moscow: Yurayt. (In Russ.)]

Новиков Л.А. Семантика русского языка. М.: Высшая школа, 1982. [Novikov, L.A. (1982). Semantika russkogo jazyka. Moscow: Vyschaya shkola. (In Russ.)]

Новиков Л.А. Избранные труды. В 2-х т. Т. І: Проблемы языкового значения; Т. ІІ: Эстетические аспекты языка. Miscellanea. М.: РУДН, 2001. [Novikov, L.A. (2001). Izbrannyie trudyi. V 2 t. T. I: Problems of linguistic meaning. T. II: Aesthetic aspects of language. Miscellanea. Moscow: RUDN. (In Russ.)]

Новиков Л.А. Художественный текст и его анализ. М.: Издательство ЛКИ, 2007. [Novikov, L.A. (2007). Khudozhestvennyj tekst i jego analiz. Moscow: Izdatel'stvo LKI. (In Russ.)]

Новикова М.Л. Остраннение как основа образной языковой семантики и структуры художественного текста. М.: РУДН, 2005. [Novikova, M.L. (2005). Ostranneniye kak osnova obraznoj jazykovoj semantiki i struktury khudozhestvennogo teksta. Moscow: RUDN. (In Russ.)]

Солнцев В.М. Язык как системно-структурное образование. Изд. 2-е, доп. М.: Наука, 1977. [Solntsev, V.M. (1977). Jazyk kak sistemno-strulturnoye obrazobaniye. Izd. 2-e, dop. Moscow: Nauka. (In Russ.)] 
Соломончик А.Б. Язык как знаковая система. Изд. 2-е. М.: Книжный дом «ЛИБРОКОМ», 2010. [Solomonchik, A.B. (2010). Jazyk kak znakovaya sistema. Izd. 2-e. Moscow: Knizhyj dom «LIBROKOM». (In Russ.)]

Степанов Ю.С. В трехмерном пространстве языка. Семиотические проблемы лингвистики, философии, искусства. М.: Наука, 1985. [Stepanov, Yu.S. (1985). V trekhmernom prostranstve jazyka. Semioticheskiye problem lingvistiki, filosofii, iskusstva. Moscow: Nauka. (In Russ.)]

Степанов Ю.С. Семиотика. 2-е изд. М.: ЛЕНАНД, 2014. [Stepanov, Yu.S. (2014). Semiotika. 2 ed. Moscow: LELAND. (In Russ.)]

Функциональная семантика. К 80-летию академика МАН ВШ профессора Льва Алексеевича Новикова: коллективная монография / Сост. Н.В. Новоспасская, Н.В. Перфильева. М.: РУДН, 2011. [Funktsional'naya semantika. (2011)/ K 80-letiyu akademika MAN VSH professor L'va Alekseevicha Novikova: kollektivnaya monographiya / Sost. N.V. Novospasskaya, N.V. Perfilieva. Moscow: RUDN. (In Russ.)]

Хухуни Г.Т. Переводы Библии: история и современность. М.: ИИИ МГОУ, 2015. Huhuni, G.T. (2015). Perevody Biblii: istoriya i sovremennost. Moscow: NII MGOU. (In Russ.)]

Bally, Ch. (1944). Linguistique générale et linguistique française. Edition second, refondue. Berne: A. FRANCKE S.A.

Bednárová-Gibová, K. (2018). Selected Chapters in English Lexicology. Part I: Lexical Semantics and Lexicography. Prešov: Vydavatel'stvo Prešovskej university.

Benveniste, É. (1971). Problems in General Linguistics. Trans. M.E. Meek. 2 vols. Florida: University of Miami.

Cabré, M.T. (1999). Terminology: Theory, methods and applications. Amsterdam and Philadelphia: John Benjamins,

Eco, U. (1989). La Struttura Assente. (1968). In English: The Absent Structure / trans. A. Cancogni. Cambridge, Mass.: Harvard University Press.

Guillaume, G. (1973). Principes de linguistique théoretique. Québec: Les Presses de l'Université Laval.

Hjelmslev, L. (1961). Prolegomena to a Theory of Language. Baltimore: Indiana, 1953. University Publications in Anthropology and Linguistics (IJAL. Memoir, 7). Madison: University of Wisconsin Press.

Jakobson, R. (1980). The Framework of Language. Chicago: Michigan Slavic Publications.

Lotman, J.M. (1990). Universe of the Mind: A Semiotic Theory of Culture. London: New York: I.B. Taurus \& Co Ltd.

Lotman, J.M. (2005). On the semiosphere. Sign Systems Studies, 2005, 33 (1), 205-229.

Pierce, C.S. (1994). Pierce on Signs: Writings on Semiotics. J. Hoopes (ed.). Chapel Hill, North Carolina: University of North Carolina Press.

Saussure, F. de. (1977). Cours de linguistique générale. Ch. Bally (ed.). A. Sechehaye with the collaboration of A. Riedlinger. Lausanne and Paris: Payot, 1916 / trans. W. Baskin. Course in General Linguistics. Glasgow: Fontana/Collins.

Sharifian, F. (2015). The Routledge Handbook of Language and Culture. London and New York: Routledge.

\section{Сведения об авторах:}

КРАСИНА ЕЛЕНА АЛЕКСАНДРОВНА - доктор филологических наук, профессор кафедры общего и русского языкознания РУДН, член редколлегии журнала Вестник Российского 
университета дружбы народов. Серия: Теория языка. Семиотика. Семантика / RUDN Journal of Language Studies, Semiotics and Semantics. Cфера научных интересов: теоретические вопросы языкознания, теория языка и текста; синтаксис, семантика и прагматика текста, лингвосемиотика.

Контактная информация: e-mail: krasina-ea@rudn.ru

НОВИКОВА МАРИНА ЛЬВОВНА - доктор филологических наук, профессор кафедры русского языка юридического института РУДН, член редколлегии журнала Вестник Российского университета дружбы народов. Серия: Теория языка. Семиотика. Семантика / RUDN Journal of Language Studies, Semiotics and Semantics. Cфера научных интересов: лингвистическая поэтика, художественный текст, семиотическое и семантическое моделирование, язык как семиосфера, когнитивистика.

Контактная информация: e-mail: novikova-ml@rudn.ru

\section{Bionotes:}

ELENA A. KRASINA is DSc. in Philology, Full Professor, Professor of the General and Russian Linguistics Department, Philological Faculty, RUDN University, a member of the Editorial Board of RUDN Journal of Language Studies, Semiotics and Semantics. Research interests: Theory of Linguistics; Theory of Language and Text, Syntax, Semantics and Pragmatics of Text, Linguosemiotics.

Contact information: e-mail: krasina-ea@rudn.ru

MARINA L. NOVIKOVA is DSc. in Philology, Full Professor Russian Language Department, Institute of Law, RUDN university, a member of the Editorial Board of RUDN Journal of Language Studies, Semiotics and Semantics. Research interests: Linguistic Poetics, Fictional Text studies, Semiotic and Semantic Modeling, Language as a Semiosphere, Cognitive studies.

Contact information: e-mail: novikova-ml@rudn.ru 